\title{
Building Nursing Capacity for Palliative Care at a Jesuit Catholic University: A Model Program
}

\author{
Eileen R. O'Shea \\ eoshea@fairfield.edu \\ Robin Bennett Kanarek \\ Meredith Wallace Kazer \\ Fairfield University, mkazer@fairfield.edu \\ Patrick W. Kelley \\ Tomi Thomas additional works at: https://digitalcommons.fairfield.edu/nursing-facultypubs \\ Copyright 2017 The Authors \\ This work is licensed under a Creative Commons Attribution 4.0 International License.
}

\section{Peer Reviewed}

\section{Repository Citation}

O'Shea, Eileen R.; Kanarek, Robin Bennett; Kazer, Meredith Wallace; Kelley, Patrick W.; and Thomas, Tomi, "Building Nursing Capacity for Palliative Care at a Jesuit Catholic University: A Model Program" (2017). Nursing and Health Studies Faculty Publications. 115.

https://digitalcommons.fairfield.edu/nursing-facultypubs/115

\section{Published Citation}

O'Shea, E. R., Kanarek, R. B., Kazer, M. W., Kelley, P. W., \& Thomas, T. (2017). Building nursing capacity for palliative care at a Jesuit Catholic University: A model program. Christian Journal for Global Health, 4(3), 40-46.

doi:10.15566/cjgh.v4i3.192.

This item has been accepted for inclusion in DigitalCommons@Fairfield by an authorized administrator of DigitalCommons@Fairfield. It is brought to you by DigitalCommons@Fairfield with permission from the rightsholder(s) and is protected by copyright and/or related rights. You are free to use this item in any way that is permitted by the copyright and related rights legislation that applies to your use. For other uses, you need to obtain permission from the rights-holder(s) directly, unless additional rights are indicated by a Creative Commons license in the record and/or on the work itself. For more information, please contact digitalcommons@fairfield.edu. 


\title{
Building nursing capacity for palliative care at a Jesuit Catholic University: A model program
}

\author{
Eileen R. O'Shea ${ }^{a}$, Robin Bennett Kanarek ${ }^{b}$, Meredith Wallace Kazer ${ }^{c}$, Patrick \\ W.Kelley ${ }^{\mathrm{d}}$, Tomi Thomas ${ }^{\mathrm{e}}$ \\ a DNP, APRN, PCNS-BC, CHPPN, Associate Professor, Egan School of Nursing and Health Studies, Fairfield \\ University, USA \\ ${ }^{\mathrm{b}}$ BSN, RN, President, Kanarek Family Foundation, USA \\ ${ }^{c}$ PhD, APRN, FAAN, Dean \& Professor, Egan School of Nursing and Health Studies, Fairfield University, USA \\ ${ }^{d}$ MD, DrPH, Distinguished Professor, Egan School of Nursing and Health Studies, Fairfield \\ University, USA \\ e PhD, MSW, Former Director General, Catholic Health Association of India, Director, Healing \\ Hands for India, USA
}

\begin{abstract}
The average life span is increasing, due to vast advancements in social conditions, public health, and medical care. Globally, those living with chronic and serious medical conditions can benefit from palliative care services. Yet, the workforce is insufficient to support the demand. This case study describes efforts made by one Jesuit Catholic University to build nursing capacity and to promote access to high quality, compassionate palliative healthcare.
\end{abstract}

\section{The Growing Need for Palliative Care}

A dramatic trend in global health has been the shift from short life spans due to high levels of infant and maternal mortality and fatal infectious diseases to longer life-spans with a proportionately greater burden of chronic diseases. ${ }^{1}$ For many persons with single or multiple chronic diseases, years may be spent in need of palliative care to address symptoms such as: pain, dyspnea, depression, anxiety, delirium, agitation, confusion, anorexia, constipation, nausea/vomiting, dry mouth, fatigue, insomnia, and seizures. ${ }^{2}$ Palliative care utilizes a team approach to support patients and their families faced with serious medical conditions, beginning from the point of diagnosis and continuing throughout the trajectory of illness. The focus of palliative care is not one in the same as hospice care; rather, palliative care aims to improve quality of life by preventing and relieving suffering, through early identification and assessment and treatment of various symptoms, whether physical, psychosocial, or spiritual. $^{3}$

The advancing epidemic of chronic diseases that includes diverse cancers, cardiovascular disease, strokes, and diabetes is now dominant in all but the most undeveloped countries and drives the need for palliative care. According to the World Health Organization (WHO), 40 million people need palliative care every year, but only $14 \%$ of them receive it. ${ }^{3}$ In many countries, palliative care services are simply unavailable. Researchers, Seya, Gelders, Achara, Milani, and Scholten (2011), suggest that $83 \%$ of the world population lack access to pain relief. ${ }^{4}$ Opioids, a mainstay of severe pain control, are not available in many countries

Nov 2017. Christian Journal for Global Health 4(3): 40-46 
due to lack of the political will to put into place the legal structures needed for their use.

For palliative care to be delivered, a workforce needs to be educated to provide high quality patient centric services. Few countries, including high-income nations, have a palliative care ready workforce. According to the most recent report conducted by the Worldwide Palliative Care Alliance (WPCA), most health professionals worldwide have sparse knowledge of the principles and practices of palliative care; the lack of knowledge further hinders the development and implementation of palliative care globally. ${ }^{5}$ Specifically, concerning the lack of knowledge of the principles and practices of palliative care education, the WPCA recommended: "basic palliative care training for all health professionals; intermediate training for those routinely working with patients with life-threatening illnesses; and specialist palliative care training to manage patients with more than routine symptom management needs," (p.28). ${ }^{5}$

\section{The Leading Role of Nursing in}

\section{Palliative Care}

The delivery of palliative care is a team-based endeavor and nurses are prepared to play a leading role on that team. By definition, the professional nurse:

. . encompasses autonomous and collaborative care of individuals of all ages, families, groups and communities, sick or well and in all settings. Nursing includes the promotion of health, prevention of illness, and the care of ill, disabled and dying people. Advocacy, promotion of a safe environment, research, participation in shaping health policy and in patient and health systems management, and education are also key nursing roles. ${ }^{6}$

In regards to care for the dying, the International Council of Nursing describes nurses as "uniquely prepared to offer compassionate and skilled care," and views the nurses' role as, "fundamental to a palliative approach that aims to reduce suffering and improve the quality of life for dying patients and their families through early assessment, identification, and management of pain and physical, social, psychological, spiritual, and cultural needs." 7

Nursing as a profession explicitly acknowledges the spiritual dimension of health, an integral consideration as patients face serious illness. The International Council of Nurses' Code for Nurses highlights the need to address spirituality and health, and the American Association of Colleges of Nursing calls for nursing education to include spirituality as it relates to a patient's health, healing, and well-being. ${ }^{8}$ In the U.S., nursing education at the Baccalaureate level ideally inculcates not only a sensitivity to the holistic needs of patients as persons, but also provides a foundation grounded in liberal education that includes the physical, social, mathematical, and life sciences, as well as the arts and humanities (AACN, 2008). ${ }^{9}$ Thus, nurses can support patients from widely different ethnic and religious backgrounds and may facilitate connection with spiritual leaders, if desired, to an individual or family member. While transcendent beliefs are common in many cultures, attitudes about the meaning of life and its end can be significantly different. $^{10,11,12}$ In circumstances where aggressive, life-extending treatments are an option, different religions can advance different considerations based on how they view the concept of an afterlife. ${ }^{13}$ In diverse multicultural settings and among believers and those who do not adhere to a belief system, it often falls to the nurse to recognize and react in a culturally and spiritually competent manner when patients nearing the end-of-life and their families are at peace, angry, confused, scared, or depressed.

\section{Faith-Based Institutions and Palliative}

\section{Care}

Faith-based institutions play an immense role in the delivery of health care services. One example 
of this outreach is by the Catholic Church. Managing $26 \%$ of health care facilities in the world, the Catholic Church oversees " 117,000 health care facilities, including hospitals, clinics, orphanages," in addition to " 18,000 pharmacies and 512 centers for the care of those with leprosy." "14 The Salvation Army is another example of an international organization that has made end of life care one of its priorities. $^{15}$ Extending into 127 countries, Salvationists respond to heath care concerns through more than 15,000 churches. ${ }^{15}$ Many other faith traditions sponsor high visibility health care programs in high, middle, and low-income countries.

A commitment to palliative care services in Catholic facilities comes from the highest levels of the Church. In May 2015, Pope Francis addressed the Pontifical Academy for Life and stated that palliative care "is an expression of the properly human attitude of taking care of one another, especially of those who suffer. It bears witness that the human person is always precious, even if marked by age and sickness." 16 He spoke of "the duty of honoring the elderly," which he related to the commandment to honor one's mother and father and described it "as the duty to have extreme respect and to take care of those who, because of their physical or social condition, could be left to die, or "made to die." "16 Reflective of the broad resonance of this concern for palliative care, on 30 March 2017, in Rome, an interfaith charter was put forth entitled Religions of the World Charter Palliative Care for Older People. ${ }^{17}$

\section{Palliative Care and Christian Higher Education}

The Judeo-Christian philosophy behind the delivery of health care services also inspires what should be a serious commitment of faith-based academic institutions to the education of practitioners of palliative care. While some countries have moved away from religious centric nursing programs in favor of more modern humanistic approaches, the US reports approximately one third of the four-year colleges offer nursing programs that are religiously based. ${ }^{8,}{ }^{18}$ Increasingly, nursing education takes place at four-year colleges and that allows the student nurse to benefit from complementary education in theology, philosophy, culture, social sciences, and communication. The juxtaposition of these disciplines fosters in the student an intellectually grounded perspective that reflects the sanctity of life at all of its stages and professional practices that respect a patient's dignity while minimizing suffering.

In the U.S., preparing nurses to provide high quality palliative care has been widely supported by several leading healthcare professional organizations. ${ }^{19,20,21,22}$ Specifically, the American Association of Colleges of Nursing has recommended the incorporation of essential palliative nursing concepts, learning objectives, content, and competencies within curricula of all undergraduate nursing programs. ${ }^{23}$ The goal of this undergraduate focus is to prepare future nursing professionals with the knowledge and skills to provide general palliative care to those with a serious illness, as the present numbers of palliative healthcare professionals available cannot meet the present needs. ${ }^{24}$ Additionally, the American Nurses Association (ANA) issued a Call to Action for all registered nurses and advance practice nurses to support and advance primary palliative nursing care. ${ }^{25}$ The ANA recommendations have educational implications to enhance graduate level curricula with palliative care education.

While these recommendations were written with an American audience in mind, they are similar to international trends. ${ }^{26,27,28}$ Faith-based academic institutions should be in the forefront of the response to this call for building up the capacity for palliative care. As institutions that share a common sense of mission and attachments to global institutional networks, (e.g., Catholic Church and Salvation Army) they are particularly well suited to work together to achieve palliative care progress globally. 


\section{Genesis of the Kanarek Center for}

\section{Palliative Care Nursing Education}

In response to the growing need to develop a general palliative care ready nursing workforce and in an effort to address the lack of education, one Jesuit school of nursing located in Fairfield, Connecticut in the United States has taken action to meet these demands. The Marion Peckham Egan School of Nursing and Health Studies at Fairfield University strives to: develop nursing professionals who are morally reflective providers, working to deliver evidenced-based holistic care to patients and families with consistent sensitivity to cultural differences and issues of social justice. ${ }^{29}$ The strong core curriculum steeped in ethics, communication, philosophy, theology, humanities, math, and science prepares Fairfield nursing students with comprehensive education necessary to become excellent nursing professionals. ${ }^{29}$ Integrating palliative care education into the Fairfield curriculum became a priority goal to respond to local and national workforce needs.

Through a generous donation, the Egan School of Nursing and Health Studies established an innovative center of nursing excellence for evidence-based palliative and end-of-life care education, named the Kanarek Center for Palliative Care Nursing Education (KCPC). This center of nursing education seeks to transform palliative care by developing the next generation of specialized leaders in the field by integrating high quality palliative nursing education into clinical practice. Specifically, the center utilizes the End-of-Life Nursing Education Consortium (ELENC) curricula to enhance both the undergraduate and graduate curricula. ${ }^{30}$ The ELNEC program was chosen as the curricula model as it continues to be revised by national palliative care experts and incorporates evidence-based practices and research on a regular basis, which allows for easy adoption into nursing curricula inside and outside of the US. ${ }^{30}$ Additionally, the KCPC center offers the ELNEC program to community clinical agencies, so that practicing licensed nurses have the opportunity to engage in continuing education concerning palliative care. Extending this education to practicing nurses will further generate consumer and provider driven communication that serves as a regional and national resource to inspire understanding of best practices in palliative and end-oflife care.

The Kanarek Center for Palliative Care Nursing Education has several notable aspects. First, the focus is to advance nursing leadership and foster inter-professional collaboration that will enhance the lives of patients with serious illness and families through education, administration, practice, research, and policy. ${ }^{31}$ Second, because the palliative care nursing education center is based within the nursing school of a faith-based liberal arts-oriented university, it has some advantages over other palliative programs based in tertiary care academic medical centers. These advantages include close relationships with community-based agencies, the faith-based community, and various outpatient settings. ${ }^{29}$ The comprehensive university setting also facilitates multi-disciplinary engagement with fields as diverse as counseling, communication, applied ethics, theology, the social sciences, engineering, and business. ${ }^{32}$ Third, the core values of this palliative care nursing education center were developed purposefully to align closely with the holistic, Judeo-Christian values that underpin the entire University mission. ${ }^{29,32}$

Of note, the idea of having a palliative care nursing education center at the Egan School of Nursing was conceived by the Kanarek family 15 years after their son's death following a five year battle with cancer. This family's commitment stemmed from the Judeo-Christian values that they hold in common with the University. Their recognition of the desperate need for better palliative care nursing education was born out of the lack of psycho-social, spiritual support during their son's final months of life. As a nurse and alumna of Fairfield University, Mrs. Kanarek, was motivated to show leadership by establishing the 
center. Admittedly, without the philanthropic support, a center of this magnitude may not have been feasible.

\section{Leading the Way: Palliative Care in Christian Higher Education}

To meet the global need to provide high quality compassionate care for patients with serious and life threatening medical conditions, a palliative care nursing workforce must be cultivated. All nursing students should graduate ready to deliver primary level palliative care. This education should address not only clinical topics such as pain and symptom management but also ethical issues, communications, spirituality, and leadership. Nurses also should fill a leading role in educating the larger lay population in what palliative care offers and in preparing all to make informed choices around palliative care and end-of-life decisions. Developing a Center of Palliative Care Nursing Education within faith-based schools of nursing may be an innovative solution to address the growing need. Measuring outcomes for this new program is needed and, if successful, may offer opportunities for replication within the U.S. and in other countries. Cooperation among faith-based nursing schools can be based on shared values and may facilitate the spread of palliative care capacity.

\section{References}

1. World Health Organization [Internet]. Geneva. NCD surveillance. 2017. Available from: http://www.who.int/ncd_surveillance/strategy/en

2. American Association of Colleges of Nursing (AACN): End-of-Life Nursing Education Consortium (ELNEC) Core Curriculum. Symptom management. Duarte, CA. The Consortium; 2016.

3. World Health Organization [Internet]. Geneva. Palliative care fact sheet. 2017. Available from: http://www.who.int/mediacentre/factsheets/fs402/en

4. Seya MJ, Gelders SFAM, Achara OU, Milani B, Scholten WK. A first comparison between the consumption of and the need for opioid analgesics at country, regional and global level. J Pain Palliative Care Pharmacother. 2011;25:6-18.

5. World Health Organization [Internet]. Geneva. Global atlas of palliative care at the end of life. 2011.

Available from: http://www.who.int/nmh/Global_Atlas_of_Palliative Care.pdf

6. International Council of Nursing. [Internet]. Geneva. Definition of nursing. 2002. Available from: http://www.icn.ch/who-we-are/icn-definition-ofnursing/

7. International Council of Nursing [Internet]. Geneva. Position statement: nurses' role in providing care to dying patients and their families. 2012. p 1.

Available from:

http://www.icn.ch/images/stories/documents/publicat ions/position_statements/A12_Nurses_Role_Care_D ying Patients.pdf.

8. Curry BD. Nursing education and the Catholic tradition. J Cath Heal AssoUS. 2010; Health Progress:25-8.

9. American Association of Colleges of Nursing (AACN). The essentials of baccalaureate education for professional nursing practice. 2008. Available from: http://www.aacn.nche.edu/educationresources/BaccEssentials08.pdf

10. Inbadas $H$. The philosophical and cultural situatedness of spirituality at the end of life in India. Ind J Palliative Care. 2017;23:338-40.

11. Canfield C. Critical care nurses' perceived need for guidance in addressing spirituality in critically ill patients. Am J Crit Care. 2016; 25(3):206-211. Available at http://dx.doi.org/10.4037/ajcc2016276

12. Milligan S. Addressing the spiritual care needs of people near the end of life. Nursing Standard. 2011;26(4):47-56.

13. Doyle D, Woodruff R. Spiritual and existential distress[Internet]. In: The IAHPC manual of palliative care. $3^{\text {rd }}$ edition. IAHPC. 2013. p107-11. Available from: http://www.ehospice.com/india/Default/tabid/10675/ ArticleId/7407

14. Catholic News Agency. Catholic hospitals comprise one quarter of world's healthcare, council reports [Internet]. Sao Paulo. Vatican. 2010. p1. Available from: http://www.catholicnewsagency.com/news/catholic 
hospitals_represent_26_percent_of_worlds_health_f acilities reports_pontifical_council

15. The Salvation Army International. London. International health services [Internet]. 2017. Available from: www.salvationarmy.org/ihq/health

16. Vatican Radio. [Internet]. Vatican. Pope Francis: We must not abandon the elderly. 2015. Available from: http://en.radiovaticana.va/news/2015/03/05/pope_fra ncis we must not abandon the elderly/1127144

17. Baykov A, Bernabei R, Bhikshuni T, Blanchard T, Brown B, Busch CJ, et al [Internet]. Rome. Religions of the world charter - palliative care for older people. 2017. Available from: http://olderpeoplereligionsworldcharter.maruzza.org

18. Tveit B, Karvinen I, Damsma-Bakker A, Ylonen M, Oosterhoff-Zielman M, Fanuelsen O et al. Balancing identity and diversity in faith-based nursing education: a case study from northern Europe. Christ Higher Ed. 2015;14:283-97.

19. National Consensus Project for Quality Palliative Care. Clinical practice guidelines for quality palliative care. 3rd ed. Pittsburgh, PA: National Consensus Project; 2013.

20. Hospice and Palliative Nurses Association [Internet]. Position statement: palliative nursing leadership. Pittsburgh, PA. HPNA; 2015. Available from:

http://hpna.advancingexpertcare.org/wpcontent/uploa ds/2015/02/Position-Statement-on-PalliativeNursing-Leadership.pdf

21. Institute of Medicine. Dying in America: improving quality and honoring individual preferences near the end of life. Washington, DC: The National Academies Press; 2015.

22. American Nurses Association and Hospice and Palliative Nurses Association. Palliative nursing: scope and standards of practice - an essential resource for hospice and palliative nurses. 5th ed. Silver Spring, MD: The Association; 2013.

23. American Association of Colleges of Nursing [Internet]. CARES: competencies and recommendations for educating undergraduate nursing students - preparing nurses to care for the seriously ill and their families. Washington, DC: AACN; 2016.

Available from:

http://www.aacn.nche.edu/elnec/New-PalliativeCare-Competencies.pdf
24. Coyle N. Introduction to palliative nursing care. In: Ferrell BR, Coyle N, Paice J, editors. Oxford textbook of palliative nursing. 4th ed. New York, NY: Oxford University Press; 2015:3-10.

25. American Nurses Association [Internet]. Professional issues panel report. Call for action: nurses lead and transform palliative care. Silver Spring, MD: ANA; 2017. Available from: http://nursingworld.org/MainMenuCategories/ThePr acticeofProfessionalNursing/Palliative-Care-Callfor-Action/Draft-PalliativeCareProfessionalIssuesPanel-CallforAction.pdf

26. Gamondi, C, Larkin P, Payne S. Core competencies in palliative care: an EAPC white paper on palliative care education - parts $1 \& 2$. Eur J Palliative Care [Internet]. 2013;20(2). Available from: http://www.eapcnet.eu/LinkClick.aspx?fileticket=XP $\underline{\text { rM1LNaSbo\%3d\&tabid }=38}$

27. Doyle D, Woodruff R. Education and training for service staff. In: The IAHPC manual of palliative care. $3^{\text {rd }}$ edition. Houston, Texas: IAHPC; 2013. p.112-3.

28. Pastrana T, Wenk R, DeLima L. Consensus-based palliative care competencies for undergraduate nurses and physicians: a demonstrative process with Colombian universities. J Palliat Med. 2016;19(1):76-82. Available from: http://dx.doi.org/10.1089/jpm.2015.0202

29. Fairfield.edu [Internet]. Fairfield, CT: Egan School of Nursing and Health Studies. Available from: https://www.fairfield.edu/undergraduate/academics/s chools-and-colleges/egan-school-of-nursing-andhealth-studies/administration-and-faculty

30. American Association of Colleges of Nursing (AACN): End-of-Life nursing education consortium (ELNEC) fact sheet [updated 2016]. Duarte, CA. The Consortium; 2003. Available from: http://www.aacnnursing.org/Portals/42/ELNEC/PDF /FactSheet.pdf

31. Fairfield.edu [Internet]. Fairfield, CT: Kanarek Center for Palliative Care Education. Available from: https://www.fairfield.edu/undergraduate/academics/s chools-and-colleges/egan-school-of-nursing-andhealth-studies/kanarek-center-for-palliative-care

32. Fairfield.edu [Internet]. Fairfield, CT: Mission, values and history. Available from: https://www.fairfield.edu/about-fairfield/missionvalues-history 


\section{Peer Reviewed}

Competing Interests: None declared.

Correspondence: Eileen R. O'Shea, Fairfield University, USA. eoshea@fairfield.edu

Cite this article as: O'Shea ER, Kanarek RB, Kazer MW, Kelley PW, Thomas T. Building nursing capacity for palliative care at a Jesuit Catholic University: a model program. Christian Journal for Global Health. Nov 2017; 4(3):40-46. https://doi.org/10.15566/cjgh.v4i3.192

(C) O'Shea ER, Kanarek RB, Kazer MW, Kelley PW, Thomas T. This is an open-access article distributed under the terms of the Creative Commons Attribution License, which permits unrestricted use, distribution, and reproduction in any medium, provided the original author and source are properly cited. To view a copy of the license, visit http://creativecommons.org/licenses/by/4.0/ 